\title{
Un acercamiento teórico: ¿Por qué y para qué investigar las características de la creatividad artística de los estudiantes en el Departamento de Artes de la Universidad Surcolombiana?
}

\author{
JAIME RUIZ SOLÓRZANO
}

Los programas de arte se iniciaron como cursos de extensión, en el hoy reestructurado Instituto Huilense de Cultura durante la década de 1980, posteriormente se firmó un convenio entre la Universidad Surcolombiana (USCO) y el Instituto Huilense de Cultura $(1 \mathrm{HC}$ ) para ofrecer programas de licenciatura, los cuales fueron debidamente aprobados por el Instituto Colombiano para el Fomento de la Educación Superior (ICFES). A partir de 1994 los programas de Artes Visuales, Arte Escénico y Música, fueron asumidos en su totalidad académica y administrativamente por la Universidad. Hoy cuenta con cuatro cohortes de egresados en cada uno de los programas.

Durante los procesos académicos se ha venido observando que en los respectivos campos específicos, es decir, los dedicados a potenciar la producción artística y el planteamiento de propuestas creativas son deficientes, en un alto porcentaje; a manera de ejemplo: durante el desarrollo de talleres como dibujo, grabado, pintura, escultura, cerámica, diseño gráfico, fotografía, producción audiovisual o expresión multidimensional, se presentan resistencias ante las exigencias del trabajo programado; de igual forma, la actitud hacia la teoría del arte, no siempre es positiva cuando se plantean retos a la creatividad; también de veinte estudiantes que cursan actualmente el último semestre de Artes Visuales, tan sólo tres o cuatro, elaboran trabajos novedosos dentro de las tendencias vigentes del arte actual.

Dicha situación es preocupante en la medida que uno de los propósitos de la educación artística propende por formar para adquirir el derecho de producir y gozar estéticamente del arte en sus distintas expresiones, superando el hecho de ser únicamente consumidores; igualmente, dentro del perfil del egresado se pretende formar licenciados creativos para el desarrollo del arte y la cultura en el ámbito regional. 
En este contexto desde la educación artística, la formación artística y la educación por el arte, es posible implementar prácticas contraculturales. entendidas como la ruptura de la cultura de masas homogenizante, que involucren de manera dialéctica y creativa las contradicciones apremiantes. Respecto a la educación artística, el arte puede contribuir al cambio de auto percepción requerida por nuestros pueblos para superar la subvaloración de sus raíces, que una educación aculturadora cimentó. La consecución de este objetivo, debe motivar reflexiones con respecto a las estrategias pedagógicas que se instrumenten para la educación artística, como un componente estratégico para la dinamización de la cultura.

Como principio epistemológico se acepta de manera tácita o explícita que existen múltiples definiciones de cultura y que ninguna es definitiva o ab-

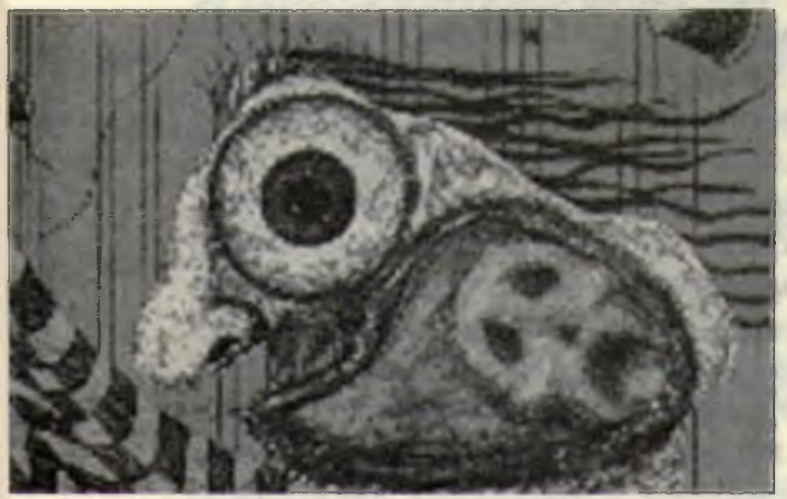

soluta. Él término cultura proviene del latín Colere como sentido de cultivo o Cultus Anima cuyo significado es armonizarse o cultivar una naturaleza predeterminada. En la modernidad, la noción de cultura considera que la misma, nos independiza de la naturaleza animal para configurar lo verdaderamente humano, acorde con el proyecto de la ilustración.

Actualmente existen más de doscientas cincuenta definiciones de cultura, por lo cual se ha propuesto tipificarlas de acuerdo con los contenidos imbricados en ellas; de esta manera, existen definiciones descriptivas, axiológicas, objetivizantes, simbólicas, antropológicas y holísticas?.

Sea cual sea el tipo de concepción respecto a la cultura, se acepta que el sentido de la cultura radica en las relaciones dinámicas, fruto de las interacciones hombre-naturaleza y hombre-hombre como praxis concreta de la humanidad. Se acepta que el trabajo fundamental de la cultura, consiste en organizar estructuralmente el mundo que rodea al hombre. Es así, como crea alrededor del hombre una socioesfera que, al igual que la biosfera, hace posible la vida, no orgánica obviamente, sino de relación.

En general, la función de la cultura en primera instancia, le posibilita al hombre situarse en el contexto histórico, geográfico y social, es decir, ubicarse en el tiempo, en el espacio y en la colectividad a la cual pertenece; en un segundo momento le permite interpretarse dentro del mundo simbólico y sus múltiples interacciones; en tercer lugar le facilita orientar su proyecto existencial y sus actividades intelectuales, productivas y colectivas.

La cultura, también cumple funciones mediadoras entre el hombre y el medio facilitando la adaptación de los 
nuevos individuos. Para ello, los sistemas culturales recurren a tres recursos: la tecnología o sea el conjunto de instrumentos, herramientas, utensilios y las técnicas para su uso; la organización social y sus correspondientes instituciones y una ideología cohesiva. mediante la cual se determinan las conductas de los individuos, de tal forma que cada cual decida hacer lo que desee. Es a través de la dinámica social y del uso de dichos medios, como es posible la adaptación, entendida como el ajuste a las condiciones de existencia y al desarrollo como proceso mediante el cual la sociedad se vuelve más heterogénea y compleja².

Desde esta perspectiva, el mecanismo por medio del cual las sociedades transmiten su cultura es la educación, la cual se concibe como un proceso social donde se seleccionan los contenidos y la visión del mundo relevante para ser compartidos y dinamizados por las nuevas generaciones, con el fin de asegurar la continuidad y cohesión de la sociedad.

Frente a la creatividad artística, comúnmente se cree que los potenciales creadores no requieren participar en procesos educativos o re-educativos; lo cual se considera un error, ya que la "inspiración" artística y el "hacer silvestre" no son suficientes. Requiere del desarrollo de la maestría manual, de experiencias sensoriales y sensitivas correspondientes a los procesos de formación y de educación artística.

Respecto a la educación artística. la consecución de este objetivo debe motivar reflexiones inherentes a las estrategias pedagógicas, que se instru- menten para el desarrollo de las capacidades sensoriales y perceptivas, además de los conocimientos históricos y conceptuales de las diferentes disciplinas y ciencias que han abordado el arte. Se debe aclarar, que si bien la implementación de las mismas, no determina de por sí la creación, si la facilita, cuando se efectúa una debida apropiación.

Está comprobado, que a través de procesos educativos pertinentes al desarrollo de la pericia manual y de obtener experiencias sensitivas y sensoriales, se permite la ejecución o materialización de obras, mientras el adquirir conocimientos históricos y conceptuales actualizados, posibilita la elección de los distintos géneros expresivos y las tendencias, con lo cual se pueden articular los lenguajes creativos personales.

Por estas razones, asumimos la posición de Howard Garnerd, sobre su tesis de las "Mentes Creativas", construida sobre dos ejes. Por una parte, Garnerd utiliza una aproximación conceptual a la creatividad que denomina "perspectiva interactiva", y por otra, emplea su "teoría de las inteligencias múltiples". En el primer eje, establece tres niveles de análisis que son: la persona con sus valores y capacidades, el saber con su respectivo sistema de símbolos en el que se desempeña y el contexto social con los profesionales. orientadores y competidores que se pronuncia sobre la calidad y validez de los productos y de la persona; en otras palabras, se busca interpretar las tensiones y conflictos; la manera como interviene, transforma o innova en su 
campo; y las relaciones de ámbito socio cultural. Desde este horizonte de análisis, la creatividad se dinamiza en los vértices del triángulo de la creatividad conformado por el Individuo, el Campo y el Ámbito ${ }^{3}$.

Es en el quehacer artístico, donde se evidencian los "pares de acción": arte/creación, técnica/normatividad, independencia/actividad controlada, y por último habilidad/imaginación, como invariantes de principios en una concepción pedagógica capaz de acentuar, según los niveles y tipo de enseñanza, las funciones reproductoras, descubridoras o inventoras del sujeto protagónico del arte, es decir, la creación ${ }^{4}$.

Considerados los aspectos anteriores nos podemos preguntar:

¿Cuáles son las características de los Individuos, del Campo artístico y del Ámbito de desempeño, determinados para analizar la creatividad de los estudiantes de los programas de arte de la USCO?

¿Cuáles son los referentes teóricos, que orientan las prácticas pedagógicas de los programas de arte de la USCO?

¿De qué manera se desarrolla la capacidad creadora, en la producción artística de los programas de arte de la USCO?

En síntesis: Lcuáles son las características de la expresión creadora, en los núcleos específicos de los estudiantes de Artes Visuales. Arte Escénico y
Música de la Facultad de Educación de la Universidad Surcolombiana?.

Para lo cual es necesario aclarar que el aprendizaje y la enseñanza del arte son factibles de abordar en tres modalidades distintas: la educación artística, la formación artística y la educación por el arte, que aunque tiene nexos sólidos son bien particulares. La educación artística, se diferencia como actividad pedagógica de integración a la escolarización sin fines de especialidad artística; la formación artística, corresponde a la actividad pedagógica dirigida a la profesionalización de la producción artística; y la educación por el arte como actividad pedagógica, busca facilitar los procesos de aprendizaje enseñanza, de cualquier saber a través de los lenguajes artísticos 5 .

El presente proyecto se enmarca dentro de la primera modalidad. En los programas que se adelantan en la USCO. los núcleos curriculares de formación se establecen en las correlaciones institucionales, psico-pedagógicas y específicas; ésta con dos áreas, una teórica y otra técnico-expresiva.

La necesidad de adelantar el presente proyecto, se origina en los objetivos que direccionan los procesos de formación en los programas de Artes Visuales Arte Escénico y Música del Departamento de Artes de la Facultad de Educación.

Respecto a los objetivos diseñados para los anteriores programas se pretende:

3 GARDNER, Howard. "ESTRUCTURAS DE LA MENTE. TEORÍA DE LAS INTELIGENCIAS MúltTIPLES". Bogotá, ED. FCE., 1999

4 HORTA MESA. Aurelio A. "EL COMPONENTE PEDAGÓGICO EN LA FORMACIÓN ARTÍSTICA Y CULTURAL". Memorias Primer Seminario de Formación Artística y Cultural. Ministerio de Cultura. Bogotá, ED. Imprenta Nacional de Colombia, 2000, p.86.

5 Ibídem, p. 87. 
- Impulsar la creación de programas y proyectos que busquen recuperar los valores, la identidad cultural y el desarrollo humano.

- Preparar artistas creativos que generen investigación y experimentación permanente.

Estos objetivos, como se enuncia en el planteamiento del problema, se están cumpliendo de manera parcial.

Además el perfil ocupacional de los programas de arte garantizan, entre otros, los siguientes campos de acción. una vez los estudiantes cursen las distintas carreras:

1. Como docente en las asignaturas de educación artística en las modalidades formal, no formal e informal.

2. Participará como organizador o integrante de grupos artísticos en las instituciones y en la comunidad.

3. Podrá ejercer su profesión individualmente según su interés de proyectarse en cada aspecto de su experiencia.

4. Formará parte o creará sociedades artísticas profesionales, escuelas 0 academias legalmente constituidas.

5. Participará en la creación, realización y evaluación de proyectos sobre educación y extensión artística.

6. Será el docente, artista creativo que vinculará los medios masivos de comunicación /cine, video, televisión y radiol local, regional y nacional.

En estos aspectos se presentan notorias inconsistencias; por ejemplo, un alto porcentaje de egresados se ha dedicado totalmente a la docencia, mientras unos pocos se dedican a producir y dinamizar la cultura, cuyas cau- sas se busca indagar. Como quedó registrado con anterioridad, la producción artística es un componente substancial en la educación artística, de aquí es importante revisar todos los procesos de formación en el campo específico, a partir de la comprensión del arte actual con sus distintas tendencias, lenguajes, técnicas y sus respectivos soportes teóricos para generar un arte orientado al ahora y al futuro. Es decir, la educación artística debe impulsar un arte emergente (innovador) $y$ en el peor de los casos dominante (vigente), pero nunca residual (caducol: no obstante, fundamentado en toda la tradición creativa de la humanidad.

Al respecto, el hombre desde aproximadamente el año 35 mil, en el zona franco cantábrica de Europa y desce el 12 mil antes de Cristo, en el área de Ixtapalapa en Latinoamérica. tuvo la iniciativa de dejar el registro de su existencia a través de múltiples expresiones artísticas. Los distintos saberes sobre el hombre han construido varias hipótesis que relacionan las necesidades de sobrevivencia con los imperativos metafísicos y culturales en los orígenes del arte, por lo cual son asumidas las explicaciones mágico - religiosas, lingüísticas, laborales, lúdicas, estéticas y ornamentales. Visto así, el origen del arte ha sido producto de la actividad humana, hecho por y para el hombre con funciones especificas.

De acuerdo con el enfoque sistémico, inherente a las funciones del arte establecidas a partir de la interrelación del sujeto (aspecto creador), su personalidad (aspecto psicológico), el objeto (aspecto reflexivo-informativo), y la sociedad (aspecto social), aceptamos las cuatro dimensiones establecidas: función creadora-educativa, función 
cognoscitiva-valorativa, función socioeducativa, y función comunicativa respectivamente.

Desde estos supuestos sobre el arte como producto esencialmente humano, con sus funciones concomitantes se infiere que dicha actividad puede saberse e indicar el modo como otros puedan aprenderla y desarrollarla. Se establece de este modo, que el arte se convierte en un saber aprensible $y$ enseñable.

Desde el mundo clásico hasta el momento actual, el conocimiento artístico se ha relacionado con tres categorías: "La poiesis, la praxis y la teoría; es decir; la producción, la acción y la especulación. Al saber teórico (teoría) se le asigna la responsabilidad de construir el discurso científico. aquel que enmarca el conocimiento (episteme), que guía las acciones y sustenta, por tanto, la perfección de la persona en su dimensión intelectual. El saber práctico (praxis) orienta las acciones del sujeto, desarrolla virtudes. fortalece la voluntad y por tanto construye el discurso ético y axiológico. El saber poiético dimensiona el producto externo del hombre, pero proveniente de él, bajo esferas oníricas objetivadas por el ars latino o techné griego, y consolida destrezas, dominios y talentos desde el hacer"6.

Sobre las teorías que orientan los programas de educación artística, son aceptados los planteamientos elaborados por Herbert Read para la educación estética, donde se identifican todos los movimientos culturales y los profesionales de educación artística, formación artística y educación por el arte que conciben a la persona como ser integral, creativo y libre. A partir de la integración de los distintos lenguajes artísticos, Read explica en síntesis que la educación se guiará por la obtención de los siguientes propósitos:

- La conservación de la intensidad natural de todos los modos de percepción y sensación.

- La coordinación de los diversos modos de percepción y sensación entre sí y en la relación con el ambiente.

- La expresión del sentimiento en forma comunicable.

- La expresión de forma comunicable de los modos de experiencia mental que, sino no fuera así, permanecerían parcial o totalmente inconscientes ${ }^{7}$.

Actualmente, existen varias tendencias con una larga trayectoria sobre la enseñanza del arte. La primera, conocida como Educación Artística, destaca la práctica del arte enfatizando los valores estéticos, artísticos y culturales; con dos enfoques pedagógicos direccionados por la concepción sobre el arte predominante, uno privilegia la libre expresión y el otro procesos comunicativos ${ }^{8}$.

La segunda, denominada educación Artístico-Estética, desarrollada en los Estados Unidos con el nombre de Discipline-Based-Art-Education o DBAE, que impulsa la producción artística, la estética, la crítica y la histo-

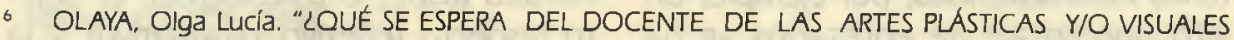
EN EL AULA7". Memorias Primer Seminario de Formación Artística y Cultural. Ministerio de Cultura. Bogotá, ED. Imprenta Nacional de Colombia, 2000, p.128.

7 READ, Herbert. "EDUCACIÓN POR EL ARTE". Buenos Aires, D. Paidós, 1991

8 Ibídem, p. 126. 


\section{5}

Paideia Surcolombiana

ria del arte. Esta tendencia es avalada por la Getty Center Foundation for Education in the Arts, donde laboran investigadores como Howard Garnerd, Elliot Eisner, Brent Wilson, Ralph Smith y Marjorie Wilson?.

Howard Garnerd informó sobre el proyecto denominado Arts PROPEL desarrollado en la Universidad de Harvard, donde se demostró la utilidad de implementar la producción, la reflexión y el desarrollo de la percepción artística ${ }^{10}$.

La educadora Drasilera Ana Mae Barbosa, interpretando las propuestas del DBAE, ha propuesto la Metodología Triangular organizada alrededor del quehacer artístico, la lectura de la imagen y la historia del arte" .

La tercera, llamada Educación Estética el arte se asume como parte de la vida cotidiana en relación con el contexto y es desarrollada con el trabajo transdisciplinario. En esta tendencia la estética de la obra de arte se integra con lo estético de lo cotidiano ${ }^{12}$.

En cualquiera de las tendencias, tanto clásicas como contemporáneas, se destaca la producción artística caracterizada por los procesos creativos fundamentados en las interpretaciones y las representaciones del mundo exterior, de la interioridad y de la revisión de la imaginería creada, desde la prehistoria a través de los distintos lenguajes artísticos y los recursos técnico-expresivos.

Sin embargo, nuestra producción artística es fruto de un largo proceso de dependencia histórico cultural. Este proceso por el cual ha atravesado nuestro país estableció la falta de autonomía y el "ser escolásticos" como secuela del avasallamiento sistemático impuesto desde la misma Conquista, con lo cual el paradigma extranjerizante fue introyectado determinando su asunción de manera consuetudinaria.

Así, el etnocentrismo hispánico impuesto como modelo racial y cultural, mediante exacciones signadas por la violencia, modeló la negación de nuestro ser cultural. Por tal razón y en secuencia fueron aceptados el francés, el inglés y finalmente el norteamericano. Bajo esta perspectiva, el anterior proceso explícita no sólo la dependencia económica, política y cultural, sino también, la negación de la posibilidad de transformación en los sectores que detentan el poder de nuestra sociedad.

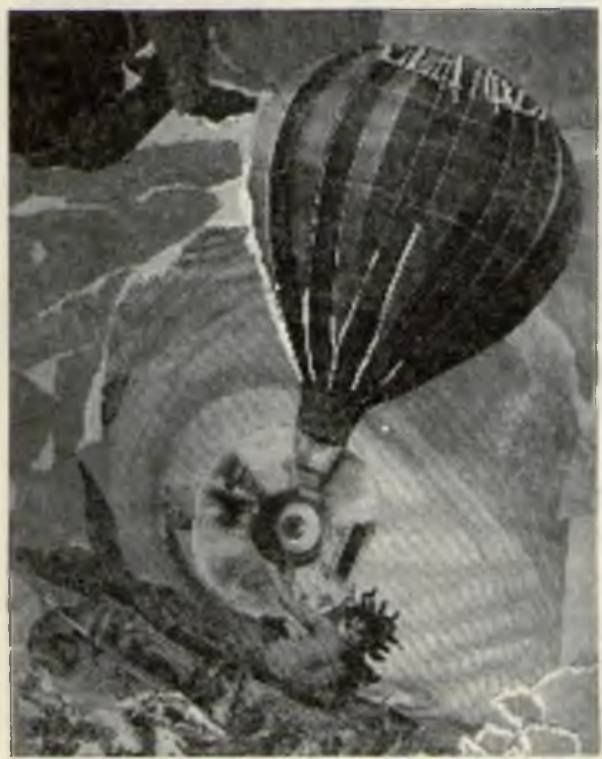

Ibídem, p. 126.

10 GARNERD, Howard. "EDUCACIÓN ARTÍstICA Y DESARROLLO HUMANO". Buenos Aires, ED. Paidós, 1994.

" Barbosa, Ana Mae. "A IMAGen nO ENSINO DE ARTE". Sao Paulo, ED. Perspectiva, 1986.

12 READ, Herbert, "EDUCACIÓN POR EL ARTE". Buenos Aires, ED. Paidós, 1999. 
Como bien se sabe, las etapas culturales enunciadas fueron y son difundidas por modelos pedagógicos signados por la dominación: Esta pedagogía de la dominación inició el sustrato de inseguridad cultural y racial que arrastraría América Latina por siglos y que dejó una huella en el psiquismo colectivo de nuestros pueblos expresados en la admiración, imitación y dependencia de la cultura blanca occidental. También generó una especie de cimarronería cultural, de códigos altamente cerrados e identificatorios, que a través del pensamiento mágico ritual así como la tradición oral subsiste en nuestros días como expresión de una cultura de resistencia. Posteriormente, en la etapa de la cultura aceptada o admitida llegaron a América los diversos patrones pedagógicos generados primero por el iluminismo, luego por la necesidad de fuerza capacitada del capitalismo industrial que nos acostumbraron a interpretar nuestros contextos socio-culturales con la lógica histórica europea y nos entrenaron a pensar y utilizar vías de acción alejadas de nuestras realidades, y que tuvieron un máximo de representatividad y gravitación continental a pesar del intento de algunos pensadores americanos que alertaban que "ni el libro europeo, ni el libro yanqui, daban la clave del enigma americano"13.

En la actualidad, asistimos a la llamada fase superior del capitalismo conocida como el proceso de globalización. Las enciclopedias en sus apartados sobre la definición de la globalización, señalan que actualmente existe una permanente interrelación entre los estados y las sociedades de todo el planeta conformando un sistema mundial. Este sistema, se identifica por conformar una trama económica global de mercados comerciales y financieros que atraviesan de hecho o de manera virtual las fronteras de los países, esto genera que lo que acontezca en algún lugar repercuta en el resto, al tiempo que las decisiones y tendencias del conjunto impactan cada lugar. Como antes lo fueron el colonialismo y el imperialismo, ahora la globalización es el resultado de la dinámica del capitalismo moderno.

El proceso de globalización se encuentra trazando profundas transformaciones en las sociedades contemporáneas. El acelerado desarrollo tecnológico y cultural, como los cambios percibidos en todas las áreas del conocimiento, están caracterizados por una compleja variedad de procesos motivados por una mezcla de influencias políticas y económicas, por nuevos sistemas y nuevas fuerzas transnacionales. Se vive una nueva etapa del capitalismo, contradictorio por excelencia. que coloca al hombre al comienzo del milenio en profundas alteraciones de la cultura, del estado, del mundo laboral y de la educación ${ }^{14}$.

Este contexto donde el saber y el conocimiento se ha erigido como valor universal debe constituir un derecho de todos y debe ser también utilizado en todas las esferas de la vida cotidiana y no sólo para producir rendimientos económicos. "El gran riesgo está en que se produzca una

13 PEREZ BIOTI, SONIA. "LA EDUCACIÓN ARTISTICA COMO ESTRATEGIA DE IDENTIFICACIÓN PARA LOS PUEBLOS LATINOAMERICANOS" En ARTE, EDUCACIÓN Y CULTURA. Fotocopias sin más datos, P. 34-35.

14 PEREIRA, María A. "DIRETRIZES PARA PENSAR UMA CONCEPÇĀO DE EDUCAÇĀO SUPERIOR NA SOCIEDADE ACTUAL". http: //umw.angelfire.com/sk/holgonsi/arleth.html, p. 2-3. 
ruptura entre una minoría capaz de moverse en ese mundo en formación y una mayoría que se sienta arrastrada por los acontecimientos e impotente para influir en el destino colectivo"15.

En este sentido, cambian los conceptos de organización económica, se transforman las instituciones y se producen nuevas necesidades sociales. En fin, son cambios radicales que al tiempo que nos fascinan, nos amedrentan. La exigencia de nuevas capacidades en ambientes complejos e inciertos. imponen al hombre más instrucción y perfeccionamiento continuo: por ello dominan conceptos como el de "educación durante toda la vida", "aprender a aprender" y "aprender a vivir juntos", como lo recomienda la UNESCO para la Educación en la agenda del siglo XXI.

Por lo cual, le cabe a la universidad la obligación de redimensionar los conocimientos, sin perder su función de generadora y transmisora de saberes en busca de sentido para la vida de la sociedad. En otras palabras, a la Educación Superior se le ha conferido el poder de determinar los procesos de construcción del conocimiento, las estrategias de acción, la selección de caminos y alternativas para la nueva cultura contemporánea o bien como desarrollo de valores, con el sentido de fomentar la formación de actitudes reflexivas, críticas y de acciones para las diversas situaciones que la globalización actual nos impone ${ }^{16}$.
Debemos recordar que a la expansión de la globalización se le opone la existencia de los estados nacionales y de políticas culturales regionales, como un obstáculo serio que se debe neutralizar según sus epígonos. Al respecto dice $A$. Hargreaves "A medida que se intensifica la globalización cuando Mc Donalds abre en Moscú, los sushi bar prosperan en Nueva York y los paisajes urbanos internacionales se parecen más en la mercantilización global de la vida de las comunidades; asistimos al resurgimiento de las identidades étnicas, religiosas y lingüísticas de carácter más local. Las identidades nacionales, puestas en peligro por la globalización económica, se están reconstruyendo frenéticamente"17.

Ante este panorama, podemos decir que "la transnacionalización no es un fenómeno puramente económico, sino un proceso que erosiona la base de los Estados nacionales, vulnera las soberanías y requiere, por lo mismo, de un aparato transnacional de comunicaciones que le permitan actuar maximizando el consenso y minimizando los conflictos"18.

Se infiere que el nuevo patrón capitalista recurre a todos los medios y mediaciones culturales para permear distintos niveles sociales en cada nación de acuerdo con su proyecto de acumulación de ganancias con "la menor inversión y en el menor tiempo posible" mientras se empeña en "ganar y monopolizar mercados y destruir a la

15 GÓMEZ B., Hernando et al. "EDUCACIÓN: LA AGENDA DEL SIGLO XXI". Bogotá, PNUD, T.M. Editores, 1998, p. 46-47.

16 PEREIRA, María A. Op. Cit., p. 3.

17 HARGREAVES, Andy. "PROFESORADO, CULTURA Y POSTMODERNIDAD". Madrid, ED. Morata. S. L., 1996, p. 81.

18 ESTEINOU M., Javier. "MÉXICO: APERTURA Y TRANSFORMACIÓN CULTURAL". http://www.iztapalapa.uam.mx/iztapala.www/topodrilo/36/td36_10.html, p.5. 
competencia". En otros términos busca formar culturalmente a los "hombres universales, a los ciudadanos del mundo", capacitados para consumir las mercaderías de los nuevos bloques de producción hegemónicos, mientras se les ofrece una supuesta identidad cultural universal a través de la denominada industria cultural.

El anterior proyecto se ha fraguado al interior del capitalismo, porque en este sistema "la cultura se convierte en una industria más. Pero a diferencia de otras industrias, la función de la industria cultural es fundamental para el mantenimiento del sistema. Es a través de la estructura y contenido de la cultura como se constituye la conciencia; y es por medio de la constitución de una conciencia reprimida como el sistema se mantiene"19.

De manera más específica, la cultura dentro del ámbito capitalista cumple una "función social interna, concreta, y es creada por medio de la compleja maquinaria artística que opera bajo la protección del sistema. Su propósito es, de una parte, afirmar las condiciones sociales existentes $y$, por otra, proporcionar una salida segura $y$ absurda al descontento - a través del arte puro- (socialmente sin sentido) ${ }^{\prime 20}$.
En este modelo cultural "la identidad nacional se debilita y la participación segmentada en el consumo se convierte en el hilo conductor que solidariza a las élites de cada país con el circuito transnacional y a los sectores populares con otros. Es decir, la separación entre grupos hegemónicos y subalternos ya no se presenta como ocurría en el pasado, principalmente como oposición entre lo propio y lo importado, o entre lo tradicional y lo moderno, sino como adhesión diferencial al subsistema cultural con diversas complejidades y capacidades de innovación: mientras unos escuchan a Santana, Sting y leen a Carlos Fuentes, otros prefieren a Julio Iglesias, Alejandra Guzmán y las telenovelas mexicanas o brasileñas de importación" ${ }^{\prime 21}$.

Sin embargo, las culturas más vulneradas corresponden a la cultura popular. Es preciso aclarar que "el cambio que está viviendo no es la destrucción de la cultura por medio de algunos productos culturales, sino el reemplazo de las culturas populares locales por productos culturales masivamente difundidos. Nada demuestra que las industrias culturales destruyan la gran cultura universalista: todo evidencia

19 FRIEDMAN, George. "LA FILOSOFIA POLITICA DE LA ESCUELA DE FRANKFURT". México, ED. F. C. E., $1986,168$.

20 Ibídem, p. 150

21 ESTEINOU M., Javier Op. Cit., p. 6. 


\section{9}

\section{Paideia Surcolombiana}

que destruye las tradiciones y las culturas locales. No existe casi ya situación alguna que un etnólogo pueda llamar tradicional e indígena. En todos lados se han transformado la alimentación, la vestimenta, las fiestas, las lenguas, mediante la penetración de elementos difundidos, sobre todo desde Estados Unidos, que conquistó un casi monopolio de la producción y de la difusión de esa cultura de masas"22.

Se puede decir que nuestras sociedades viven una profunda crisis y contradicción en su ser artístico y cultural, pues mientras en la Constitución Politica, en las instituciones estatales, en los documentos y discursos oficiales se garantiza y proclama la defensa de la identidad pluriétnica y pluricultural, las prácticas demuestran la inserción de la nación dentro del orden hegemónico internacional con la intención de construir "la Colombia de la modernidad" incorporada a la dinámica de la globalización que pretende homogenizar y masificar todas las manifestaciones y expresiones culturales.

Las denuncias respecto a la crisis de la cultura y el arte no son nuevas. Ya Georg Luckács y la Escuela de Frankfurt se habían pronunciado al respecto. Sobre esta problemática Luckács explicitó el concepto de reificación: "es decir la transformación del sujeto en objeto -es el verdadero modo de producción capitalista-. La tarea del capitalismo es la transformación del mundo en objeto. Esta es también la tarea de la ilustración. Lo que hace el capitalismo es superar la objetividad de la naturaleza propia de la ilustración a través de la objetivación del hombre"23.
Se puede decir que la hegemonía capitalista considera a la naturaleza y al hombre como simples objetos sojuzgados y desechables, como simples recursos del sistema de producción y consumo. No obstante, Luckács indica que la esencia y origen de la crisis de la cultura y el arte se centra en la "reificación de la conciencia", en lo cual coincide la Escuela de Frankfurt; es decir, que la estructura mental del hombre o la "reificación del espíritu mismo" se encuentra también cosificada, convertida en objeto. Con ello tanto la vida material como la vida interior se encuentran alienadas para servir al sistema de acumulación imperante.

La idea de la alienación es bastante antigua, pasando de su origen religioso a las escuelas clásicas de la filosofía occidental como una connotación sobre "el destino trágico del hombre" ante realidades que se escapan a su control. Dicha idea fue retomada por Hegel, pasando el fundamento antropológico y filosófico a una concepción cimentada en el trabajo, anunciando que el hombre es alienado debido a la misma condición de su trabajo igualmente alienado, por medio de dos aclaraciones: la primera o la "dialéctica de la necesidad y el trabajo del hombre", donde las necesidades siempre superan los recursos a su disposición. conllevando a las personas a trabajar duro para satisfacerlas; en la segunda - "externalización" asegura que el trabajo es la reproducción de la idea que se genera en la mente. La conclusión es que "todo tipo de trabajo es alienado, porque en cualquier sociedad, bajo cualquier condición, los hombres esta-

22 TOURAINE, Alain. "CRISIS DE LA CULTURA" en Magazín del Espectador No. 344. Bogotá, Nov. 26 de 1989, p. 20.

巴 FRIEDMAN, George. Op. Cit., p. 149-150. 
rán siempre condenados a estar separados de los productos de su trabajo"24.

Para Marx la alienación radica en las formas de organización de la economía y la sociedad en contextos espacio temporales específicos, transformando la noción antropológica de Hegel en una concepción histórica susceptible de transformar. Para tal efecto emplea tres términos de manera intercambiable, es decir, la alienación económica, la cosificación y el fetichismo. En el primero, supone la separación de las personas de los medios de producción y de subsistencia con lo cual se ven abocadas a vender su fuerza de trabajo a un sistema laboral que no posibilita expresar su potencial creativo, convirtiéndose el trabajo en una actividad sin significado, nociva y destructora. El segundo, consiste en la incapacidad de los seres para comunicarse porque las relaciones se deshumanizan, se convierten en relaciones entre posibles clientes-objetos del intercambio comercial. El tercero, es el fetiche del capital por el cual viven y trabajan las personas hecho manifiesto en la tiranía y adoración del dinero para la satisfacción de todas las necesidades ${ }^{25}$.

La Escuela de Frankfurt afirma que existe "una crisis aún más profunda. pero vinculada a la crisis cultural: la crisis de la psiquis humana", en la cual las manifestaciones culturales son solamente el "aspecto objetivo del problema del sujeto"26. Esta crisis de la psiquis de la humanidad ha conllevado al "triunfo del mal gusto y del horror", acoplado con el fracaso de la crítica cultural en la ruptura de la autocomplacencia propia de una cultura insuficiente y distorsionada, repercutiendo en las obras de arte, en la conciencia y en las instituciones ${ }^{27}$

De acuerdo con la misma Escuela, la crisis de la cultura y el arte presentan tres aspectos básicos: "el primero y más profundo es la crisis de la obra de arte, en sí misma. El arte ha sido situado en una posición insostenible. La tecnología ha destruido su autenticidad esencial y su autonomía. Ya no puede existir por sí mismo como mediación de la belleza, sino que depende de las cosas que le son exteriores. La masa, acontecimiento social creado por la tecnología, hace depender el arte de la política y a la política del arte. En cualquier caso el arte pierde su esencia; debe negar su belleza promulgando el horror fascista o tiene que rechazar la negatividad afirmando la estructura social vigente. La obra de arte perdió dialécticamente su posición anterior, pero no ha creado dialécticamente un momento nuevo que le permita seguir siendo arte.

La segunda crisis surge de la primera y es la crisis de la cultura en general. La cultura deviene afirmativa. Peor aún, gracias a la pérdida de sus componentes estéticos y de sus imperativos institucionales y políticos se vuelve mediocre. La cultura, más que configurar la conciencia, se erige como negación de la conciencia. Se establece como repetición vacía de una consigna, puesto que la repetición es la única tarea que le queda después del fracaso del arte. El estado de la cultura moderna representa el oscurecimiento de la conciencia humana $y$.

24 MANDEL, Ernest y NOVACK, George. "TEORIA MARXISTA DE LA ALINEACIÓN". Bogotá, ED. Pluma, p. 19-20. 


\section{1}

\section{Paideia Surcolombiana}

precisamente, su vaciedad, le proporciona elasticidad completa haciéndola inmune a la oposición por medio de una combinación de fuerzas y capacidad de absorción.

Por último, existe la crisis de las instituciones, la industria cultural levanta una superestructura institucional sobre la transformación tecnológica del arte y la cultura. Como respuesta a los imperativos racionalizados de toda la estructura burocrática y como respuesta a la racionalidad que sustenta el sistema económico y político en conjunto, la industria cultural es inexpugnable ante los ataques culturales y políticos"28.

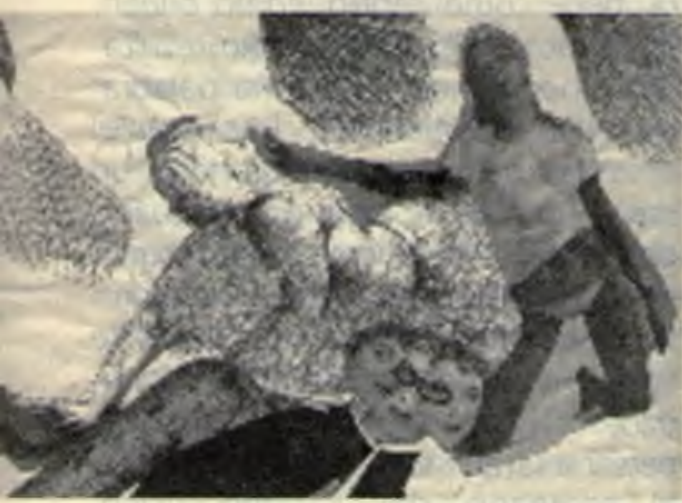

Para sintetizar, Jurgen Habermas explicó que el capitalismo convertía la cultura "en objeto de ocio, sin ningún vínculo especial con los procesos sociales" o en un saber especializado de profesionales. Al tiempo considera Habermas al arte como un potencial para relativizar la cultura hegemónica "ve en el arte una contracultura que se enfrenta a este intento del capitalismo de aislar la cultura de la sociedad y de erigir el éxito y los beneficios como criterio último"29.
De tal estado de cosas, surge la urgencia de pensar desde los diversos sectores e instituciones de la sociedad las estrategias políticas, económicas. sociales y educativas adecuadas para diseñar, defender e impulsar nuestros propios proyectos culturales ante la acelerada crisis de la cultura y el arte coadyuvada por la globalización material, mental y sensitiva en la cual se halla inmersa nuestra población.

De manera simultánea, es posible adoptar una serie de valores concomitantes con el mismo proyecto porque la cultura de un pueblo, su perfil social, se define por los valores y actitudes que se inculcan a través de los medios socializantes /las familias, las instituciones escolares, las iglesias, los medios de comunicación, etc.): los cuales pueden ser intervenidos y transformados; con el tiempo influyen de manera casi imperceptible en las distintas prácticas sociales.

Sustentados en las anteriores razones se colige que la educación debe cumplir funciones dinamizadoras de la cultura, orientada de manera crítica a develar nuestro ser histórico y nuestro estar presente, a generar proyectos pedagógicos que respondan a autenticas necesidades culturales, a implementar programas que potencien el desarrollo de las expresiones creativas. Al tiempo que motiva a justipreciar nuestros auténticos valores desde una perspectiva emancipadora.

En cuanto a la educación artística, se puede afirmar que "el arte, por incluir emoción y razón, por establecer una relación especial de subjetividad a subjetividad, puede contribuir en 
América Latina al necesario cambio de auto percepción que necesitan estos pueblos para superar los sentimientos de alejamiento y desvalorización de sus propias raíces que una educación aculturadora sedimentó durante siglos contribuyendo a un total prejuiciamiento de sus distintos valores culturales. La consecución de este objetivo debe motivar reflexiones con respecto a las estrategias pedagógicas que se instrumenten para la educación artística" 30 .

Vista así la estética, impuesta por los procesos de transculturación, desde los centros de poder a la periferia, puede ser relativizada y refuncionalizada al posibilitar la hibridación de temas, técnicas, formas, imágenes y contenidos procedentes de distintos tiempos y culturas. Es decir, que el "carácter multiideoestético del arte contemporáneo" permite la coexistencia de las expresiones culturales hegemónicas con las estigmatizadas subalternas, el cual debe ser orientado con el fin de potenciar el desarrollo de la creatividad.

Respecto de la creatividad, es pertinente aclarar las teorías clásicas de la acción que determinan tres tipos de órdenes enunciados por Aristóteles (orden teleológicol encaminando las acciones hacia fines; Kant (orden normativo) obedeciendo a una ley; $y$ Hume (orden causall como parte de una serie de causas. Esto significa que las acciones se comprenden a partir del querer o desear, del deber y del poder, respondiendo a una serie de necesidades y predisposiciones subjetivas, de normas sociales intersubjetivas y de condicionantes objetivas que origina una creatividad relativa.

De ceñirnos a dichos ordenes, la creatividad prácticamente sería nula ya que predeterminan acciones rígidas y estereotipadas. La alternativa se enmarca dentro de una creatividad contundente que desvertebre las limitaciones de cada uno de los órdenes alterando los fines. las reglas y las circunstancias al tiempo que genera una creatividad radical ${ }^{3 !}$.

Por ello aceptamos la propuesta de COLCIENCIAS, en su intención de implementar la creatividad desde la nueva concepción: "La propuesta creativa que pretendemos comunicar ahora, tiene como centro, como origen, como desarrollo y aún como resultado, fundamentalmente una palabra: DESORDENAMIENTO... Entonces el desorden del que hablamos no es un simple cambio de lugar o de actuar o de ser que normalmente cae en esquemas. Desordenar es sacudir la red simbólica en que nos movemos; y en este tipo de desorden toda la persona queda comprometida porque es toda la persona la que va a sentir el impacto. el remezón del cambio físico. contextual y de sentido. Desordenar es cambiar las concepciones que se tienen sobre las cosas..

Sin embargo, por razones tácticas proponemos comenzar por desordenar lo que tenemos a la mano: los objetos que nos rodean, los espacios en que nos movemos, las costumbres cotidianas, nuestras propias necesidades fisiológicas, nuestro vestido, las verdades. creencias o principios comunes y co-

30 PÉREZ BIOTI, Sonia. Op. Cit., p.34.

31 WALDENFELS, Bernhard. "SIMBÓLICA, CREATIVIDAD Y RESPONSIVIDAD RASGOS FUNDAMENTALES DE UNA FENOMENOLOGÍA DEL ACTUAR" en Ideas y Valores.

http://hemeroteca.icfes.gov.co/revistas/ideasval/ivI50/waldenfels.html, p.7-8. 


\section{3}

Paideia Surcolombiana

rrientes sobre los que fundamentamos nuestra vida diaria"32.

Por tales razones, se hace válido el llamamiento del Director General de la UNESCO: "En un momento en que se transforman las estructuras familiares y sociales con repercusiones a menudo negativas para nin̄os y adolescentes, la escuela del siglo $X X \mid$ debe poder anticipar las nuevas necesidades, dándole lugar privilegiado a la enseñanza de los valores y las materias artísticas para favorecer la creatividad, capacidad distintiva de los seres humanos. La creatividad es nuestra esperanza.

Hoy en día, se impone una formación más equilibrada, que ponga en pie de igualdad las disciplinas científicas, técnicas y deportivas, las ciencias humanas y la enseñanza artística en las diferentes etapas de la escolaridad. A este respecto, la actividad lúdica, como forma primordial de la actividad creativa, es uno de los factores que hay que fomentar en la enseñanza de las artes. Esta enseñanza, que no es solamente intelectual, implica tanto el cuerpo como el espíritu. pues al poner en acción los sentidos crea una memoria que agudiza la sensibilidad del niño y lo predispone a otras formas de conocimiento, en particular al de las ciencias. Además, esa enseñanza desarrolla la facultad creativa de la persona orientando su energía hacia los objetos simbólicos de su elección" ${ }^{\prime 3}$.

En el compromiso ineludible de direccionar la educación artística en el Departamento del Huila y la Región
Surcolombiana, se tienen claros los presupuestos básicos enunciados por Ana Mae Barbosa que caracterizarían la formación de los docentes en artes:

- La excelencia del arte-educación debe ser parte de un compromiso que involucre a la educación en general o macro.

- La conquista de la excelencia implica una constante búsqueda de situaciones en las cuales los alumnos aprendan a sentir el arte para comprender su dimensión histórica, apreciar su estética y realizar reflexiones con espíritu crítico.

- La preparación de los profesores debe centrarse en trabajos de contenido humanista, particularmente en las áreas de estudios históricos, filosófi$\cos y$ de crítica de arte.

- La excelencia presupone el conocimiento de las reivindicaciones tanto del arte tradicional, hegemónico, y contemporáneo, como popular ${ }^{34}$.

Fundamentados en las anteriores razones, es nuestra responsabilidad, recobrando las mejores experiencias e ideas prospectivas, diseñar propuestas pedagógicas que viabilicen los derechos culturales garantizados por la Constitución Política Colombiana (CPC) (Artículos 70, 71, 72), la Ley General de Cultura (Ley 178 de 1997) y la Ley General de Educación (Ley 115 de 1994) en el contexto huilense, a través de la cualificación de los programas de educación artística que existen en la Facultad de Educación de la USCO.

32 RUBIO, José Vicente. "CREATIVIDAD UNA NUEVA CONCEPCIÓN PARA UNA NUEVA ÉPOCACREÁTICA". nttp://muw.colciencias.gov.co/redcom/Tex-Rubio-Creatividad.htm, p. 1-16.

33 UNESCO. "LLAMAMIENTO DEL DIRECTOR GENERAL A FAVOR DE LA PROMOCIÓN DE LA ENSEÑANZA ARTISTICA Y LA CREATIVIDAD EN LA ESCUELA. 30. REUNIÓN DE LA CONFERENCIA GENERAL". Paris 3 de noviembre de 1999. nttp://wmw.unesco.org/culture/creativity/html-sp/ index-sp.htm, p. 1-2.

34 OlAYA, Olga Lucía. Op. Cit., p. 127. 